\title{
THE RÔLE OF THE EXTRACELLULAR FLUID IN THE MAINTENANCE OF A NORMAL PLASMA VOLUME
}

\author{
By JAMES V. WARREN, ARTHUR J. MERRILL, AND EUGENE A. STEAD, JR. \\ (From the Medical Service of the Grady Hospital and the Department of Medicine, \\ Emory University School of Medicine, Atlanta)
}

(Received for publication January 8, 1943)

The importance of the blood volume in maintaining a normal circulation is now well recognized. The circulation will fail if the volume of blood becomes too small to fill the vascular system adequately. In general, the quantity of blood in the vascular bed is of more significance in maintaining a normal cardiac output than is the proportion of red cells to plasma. Because the volume of plasma can be increased or decreased with relative rapidity, the body uses this means to maintain a comparatively constant blood volume. A decrease in the volume of the circulating red blood cells is normally compensated by an increase in plasma volume; and conversely, an increase in the volume of the circulating red cells is compensated by a decrease in plasma volume. Because a constant blood volume is dependent upon these compensatory adjustments in the plasma volume, a knowledge of the factors controlling the plasma volume is of both theoretical and practical importance.

If the arterial pressure, the venous pressure, and the volume of the circulating red cells remain relatively constant, the plasma volume increases and decreases as the amount of circulating plasma protein is increased or decreased. Thus, the injection of a concentrated protein solution causes a temporary rise in plasma volume (1); and the removal of plasma protein causes a temporary decrease in plasma volume, even though the fluid lost in the removal of the protein is replaced by an equal quantity of physiological saline solution (2). The changes in plasma volume produced by varying the amount of circulating plasma protein are not permanent in normal subjects because the body is able to add protein to the blood stream or remove it. When the blood volume is raised by the addition of protein, the body withdraws protein from the circulation. When the volume is decreased by lowering the quantity of circulating protein, the body adds protein to the blood stream (3).
Ebert, Stead, and Gibson (2) studied the changes in the plasma volume of normal subjects after venesection. Immediately after the removal of approximately one-fifth of the blood volume, hemodilution occurred, presumably because of the lowering of venous and capillary pressures. It has since been demonstrated (4) that the pooling of comparable quantities of blood in the extremities by tourniquets does cause a significant decrease in venous pressure. That this initial hemodilution was caused by adding to the blood stream fluid which contained little protein was shown by the parallel fall in plasma protein concentration and hematocrit reading. After one to two hours, no further fall in protein concentration occurred, though the hematocrit reading continued to decrease. This indicated that protein was being added to the blood stream. The return of the blood volume to normal was not appreciably hastened by giving physiological saline solution to replace the blood removed. Most of the saline left the blood stream and did not return to it until the quantity of circulating protein had increased. In the normal subject, there seemed to be enough available fluid to accomplish the initial phase of dilution, and after that time, a further increase in plasma volume was dependent on the addition of protein to the blood stream. Later experiments (5) demonstrated that after venesection, the blood volume could be immediately brought back to normal by replacing the removed blood by an equal volume of fluid containing albumin. These data demonstrated that in a normal subject, with a relatively constant arterial pressure, the amount of circulating plasma protein determined the size of the plasma volume and that a lowering of the quantity of circulating protein caused a decrease in plasma volume and served as a stimulus to the body for the production of plasma protein.

The above data suggested that patients with nephrosis and nutritional edema would have a very small plasma volume because of the striking de- 
crease in the quantity of circulating protein. Indeed, from the studies made in normal subjects, it would appear that the reduction in plasma volume would be so striking that the blood could not adequately fill the vascular system and circulatory failure would result. Observations on patients with nephrosis (6) and nutritional edema (7) indicated that their plasma volumes are somewhat below normal but the decrease is not marked. As the plasma volume is adequate in nephrosis to maintain a normal circulation and arterial pressure, it appears obvious that the plasma volume is maintained by some other factor in addition to the osmotic pressure of the proteins, and that this factor is not operative to any great extent in normal subjects.

Studies on patients and animals in shock have demonstrated that the plasma volume decreases as the quantity of circulating protein is diminished, and that death occurs from circulatory failure before the quantity of circulating protein has fallen to a level comparable to that which occurs in nephrosis. In patients in shock, as in normal subjects, the size of the plasma volume is affected by the amount of protein in the circulation. The most striking difference between patients with nephrosis and normal subjects or patients in shock is that the former show a marked increase in the volume of the extracellular fluid. It seems possible that the patient with nephrosis is able to maintain an adequate plasma volume because of the marked increase in extracellular fluid, while the normal subject and the patient in shock cannot maintain an adequate plasma volume because they do not have this excess extracellular fluid. The purpose of this paper is to determine the effect of the extracellular fluid volume on the size of the plasma volume.

The general plan of the experiments was to reduce the quantity of circulating protein in the blood stream by causing it to leak out through injured capillaries into the tissues, and then to increase markedly the volume of extracellular fluid in order to determine whether the plasma volume could be maintained at a normal level by a compensatory increase in the amount of extracellular fluid.

\section{METHOD}

Street dogs weighing between 5 and $16 \mathrm{kgm}$. were anesthetized by the intravenous administration of sodium pentobarbital. Rubber tubing was wrapped tightly around the proximal portions of the extremities, as close to the trunk as possible. In the first 2 experiments, the circulation was occluded to both hind extremities; in the remainder, tourniquets were placed on all 4 extremities. The tourniquets usually prevented blood from entering the leg in appreciable quantities, although, at times, sufficient blood leaked past to cause swelling of the leg. After 5 to 6 hours, the tourniquets were released. The intravenous administration of physiological saline solution was begun either immediately after the release of the tourniquets or within the first hour, and it was continued until the animal was very edematous. Infection was prevented by giving from 0.5 to 1.0 gram of sulfadiazine, intravenously, before the tourniquets were applied. At 4- to 6hour intervals after the release of the tourniquets, 0.3 gram of sulfadiazine was given intravenously.

The plasma volume, hemotocrit reading, and the plasma protein concentration were determined before the tourniquets were applied. These measurements were repeated after the plasma volume had stabilized, as shown by a constant hematocrit reading. The plasma volume was measured by the dye method of Gibson and Evans (8), adopted to the Klett-Summerson photoelectric colorimeter. Heparin was used as the anti-coagulant. The plasma protein concentration in grams per $100 \mathrm{cc}$. was calculated from the protein nitrogen, as determined by a standard micro-Kjeldahl technique (9). The venous pressure was measured directly by threading a No. 8 ureteral catheter through the external jugular vein into the superior vena cava. The mean arterial pressure was measured in $\mathrm{mm}$. of $\mathrm{Hg}$ by direct arterial puncture.

To differentiate between the effects of the trauma to the extremities and the effect of administering large quantities of physiological saline solution, experiments were performed in which the extremities were not injured. Three dogs were anesthetized with sodium pentobarbital for 5 hours and at the end of that time, an amount of physiological saline solution equal to their body weight was administered intravenously. It required from 6 to 8 hours to complete the infusion and during that time the anesthesia was maintained. The venous pressure, the plasma protein concentrations, and the plasma volume were measured before and 1 hour after the completion of the saline infusion.

\section{RESULTS}

\section{Experiments with tourniquets}

Fourteen experiments with tourniquets were performed on 13 dogs. Five dogs died, apparently from heart failure. Four of these received less than $3200 \mathrm{cc}$., while the fifth received $5500 \mathrm{cc}$. of 
TABLE I

Summary of observations on animals recovering after prolonged arterial occlusion of legs

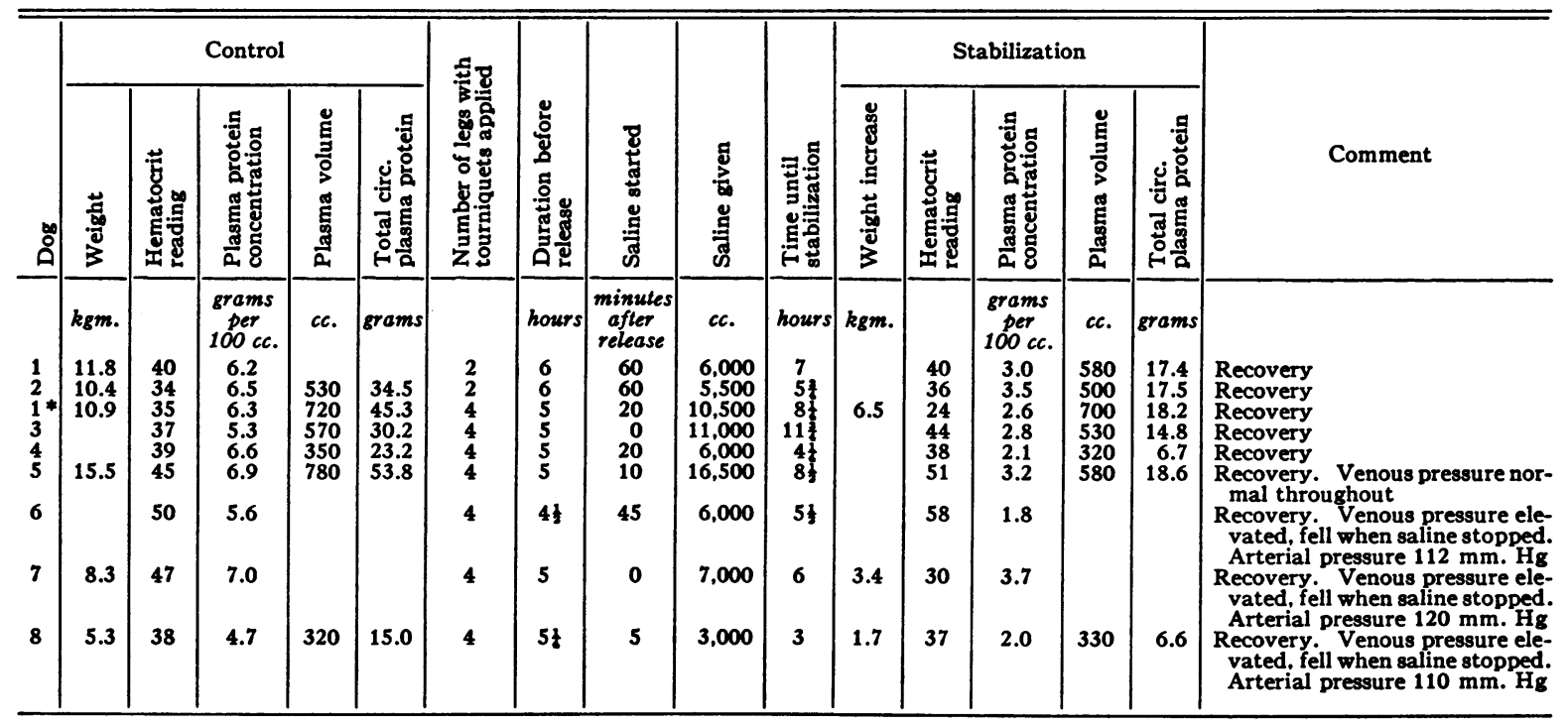

* Following recovery from the first experiment, this dog was used on a second occasion.

physiological saline solution. The heart failure appeared to result from the effects of either the anesthetic or the tourniquets, and not from the administration of saline. These data will be reported later. The animals recovered in 9 instances, and these experiments form the basis of this report (Table I).

As noted by other observers $(10,11)$, the arterial pressure fell when the tourniquets were released, the legs became swollen, and the hematocrit reading rose. There was at times a moderate increase in plasma protein concentration. The marked rise in hematocrit reading without a corresponding increase in the protein concentration indicated that protein, as well as fluid, was leaving the blood stream. The marked swelling of the extremities showed that the leak was occurring in capillaries which had been damaged by the prolonged arterial occlusion. In the dogs that recovered, the circulation improved as soon as saline was given and remained adequate as long as the saline administration was continued. The infusion was given at a rate of 1 to 2 liters per hour, so that each dog received from 3 to 16.5 liters of saline in a period of from 3 to 12 hours. After 1 to 2 hours, the dogs voided copiously; therefore, a variable portion of the administered fluid was lost through the kidneys. The extremities became warm and very swollen. Later, generalized edema developed, which was most apparent around the eyes. It was never as marked as in the injured legs. If the administration of saline was stopped before the edema became generalized, the plasma volume decreased rapidly, as shown by the steady rise in the hematocrit reading to a level much higher than that present before the tourniquets were applied. When the eyelids were swollen, the infusion was stopped. After 30 minutes, blood was drawn for an hematocrit reading. This was done 3 times at 30-minute intervals. The plasma volume was determined when the hematocrit reading became stabilized.

The plasma volume was determined before the application of the tourniquets and after the administration of saline in 6 experiments. In 5 of these, there was no significant change. In 1 experiment, sufficient saline was not given to bring the hematocrit reading back to the control level and the plasma volume was smaller at the end of the infusion. In 3 experiments, plasma volume studies were not done, but the hematocrit readings indicated that a marked degree of hemoconcentration was not present.

After the plasma volume had become stabilized, the plasma protein concentration was strikingly lowered. In the 6 experiments in which measure- 
ments were made, the amount of total circulating protein at the end of the experiments ranged from 29 to 51 per cent of the quantity present before the application of the tourniquets. All of the dogs had hemoglobinemia and hemoglobinuria. In 2 experiments, the hematocrit readings were considerably lower after the infusion than before the application of the tourniquets. In 1 of these 2 dogs in which it was measured, the plasma volume was not increased. This indicated a measureable destruction of red cells.

None of the dogs showed any signs of circulatory insufficiency after the plasma volume was stabilized, and at no time was there evidence of pulmonary edema. In 3 of the 4 experiments in which the venous pressure was measured, it rose while the saline was being given but fell to normal shortly after the infusion was stopped. In the fourth, the venous pressure remained normal throughout. After the plasma volume had become stabilized, the mean arterial pressure was measured in 3 dogs and found to be normal. In the 3 dogs which were weighed, the body weight had increased 32, 41, and 60 per cent.

In the 12 to 24 hours following the infusion, the amount of plasma protein increased rapidly. The dogs diuresed and after a few days became edema-free. The destruction of red cells continued, however, and the hematocrit reading decreased steadily for the next 72 hours. The legs were completely paralyzed for several days but function gradually returned, and at the end of a few weeks, the dogs were able to walk.

\section{Experiments without tourniquets}

After 5 hours' anesthesia, 3 dogs were given intravenously an amount of physiological saline solution equivalent to their body weight. From
6 to 8 hours were required to complete the infusions. After the first 2 liters, the dogs voided profusely. The eyelids became somewhat edematous and the head and body appeared puffy. There was no pitting edema. The massive localized edema of the extremities, which appeared quickly in the dogs whose legs were injured by the tourniquets, did not occur. One hour after the infusion was completed, the dogs had gained from 1.8 to $4.2 \mathrm{kgm}$. in weight. The venous pressure was unchanged in 2 dogs and $8 \mathrm{~cm}$. higher than the control level in 1 . The protein concentration was moderately lowered and the plasma volume either unchanged or slightly larger than before the saline solution was given. The amount of total circulating protein ranged from 74 to 91 per cent of that present before the saline was given. The edema rapidly disappeared and after 24 hours, the animals appeared to be in a normal state.

\section{COMMENT}

The prolonged arterial occlusion caused damage to the capillaries in the extremities. When the tourniquets were released, protein leaked out into the legs. In a preparation of this type, the faster the circulation, the greater the protein loss in the injured areas. In these experiments, there was no evidence of circulatory failure after the infusion was started, and protein and fluid continued to pass into the legs until they became tight with edema. As the skin of the extremities became tight, the rate of swelling decreased. Though the fluid and protein loss into injured areas was now greatly decreased, an adequate plasma volume could not be maintained if the infusion was stopped at this time, because the plasma protein concentration was now so greatly lowered that fluid was passing from the blood stream into the tissues of

TABLE II

Summary of observations on uninjured anesthetized animals receiving saline solution

\begin{tabular}{|c|c|c|c|c|c|c|c|c|c|c|c|c|}
\hline \multirow[b]{2}{*}{ Dog } & \multicolumn{5}{|c|}{ Control } & \multirow[b]{2}{*}{$\begin{array}{l}\text { Saline } \\
\text { given }\end{array}$} & \multirow[b]{2}{*}{$\begin{array}{c}\text { Time } \\
\text { required }\end{array}$} & \multicolumn{5}{|c|}{ One hour after infusion } \\
\hline & Weight & $\begin{array}{c}\text { Hemato- } \\
\text { crit } \\
\text { reading }\end{array}$ & $\begin{array}{l}\text { Plasma } \\
\text { protein } \\
\text { concen- } \\
\text { tration }\end{array}$ & $\begin{array}{l}\text { Plasma } \\
\text { volume }\end{array}$ & $\begin{array}{c}\text { Total } \\
\text { circ. } \\
\text { plasma } \\
\text { protein }\end{array}$ & & & $\begin{array}{c}\text { Weight } \\
\text { increase }\end{array}$ & $\begin{array}{c}\text { Hemato- } \\
\text { crit } \\
\text { reading }\end{array}$ & $\begin{array}{l}\text { Plasma } \\
\text { protein } \\
\text { concen- } \\
\text { tration }\end{array}$ & $\begin{array}{l}\text { Plasma } \\
\text { volume }\end{array}$ & $\begin{array}{l}\text { Total } \\
\text { circ. } \\
\text { plasma } \\
\text { protein }\end{array}$ \\
\hline & kgm. & & $\begin{array}{c}\text { grams per } \\
100 \text { cc. }\end{array}$ & $c c$. & grams & $c c$. & hours & kgm. & & $\begin{array}{l}\text { grams per } \\
100 \text { cc. }\end{array}$ & $c c$ & grams \\
\hline $\begin{array}{l}1 \\
2 \\
3\end{array}$ & $\begin{array}{l}13.6 \\
10.2 \\
10.5\end{array}$ & $\begin{array}{l}42 \\
42 \\
37\end{array}$ & $\begin{array}{l}5.9 \\
5.0 \\
5.5\end{array}$ & $\begin{array}{l}670 \\
530 \\
550\end{array}$ & $\begin{array}{l}39.5 \\
26.5 \\
30.2\end{array}$ & $\begin{array}{l}14,500 \\
10,000 \\
10,500\end{array}$ & $\begin{array}{l}6 \\
8 \\
7 \frac{1}{2}\end{array}$ & $\begin{array}{l}4.2 \\
2.7 \\
1.8\end{array}$ & $\begin{array}{l}42 \\
43 \\
41\end{array}$ & $\begin{array}{l}4.2 \\
4.7 \\
4.3\end{array}$ & $\begin{array}{l}695 \\
520 \\
600\end{array}$ & $\begin{array}{l}29.2 \\
24.2 \\
25.8\end{array}$ \\
\hline
\end{tabular}


the entire body. The osmotic pressure of the proteins was no longer sufficient to support an adequate blood volume. In time, generalized edema developed, and eventually, the plasma volume remained adequate to maintain a normal circulation, in spite of the great decrease in the quantity of circulating protein. The amount of generalized edema that had to be formed before an adequate plasma volume was maintained seemed to vary with the dogs. In the animals with the tight skins, the plasma volumes became stabilized with much less visible swelling than in those with loose skins. Though the pressure of the extracellular fluid was not measured, it probably rose as the volume of the fluid increased, because, in these acute experiments, there was not sufficient time to have destroyed an appreciable amount of tissue. In prolonged experiments, a loss of tissue substance would allow the accumulation of large quantities of extracellular fluid without increasing the pressure of the extracellular fluid. In addition to the increase in the volume and pressure of the extracellular fluid, production of plasma protein by the body and the return of the protein from the tissues of the injured extremities by way of the lymphatics probably helped to stabilize the plasma volume.

The question arose as to whether a fall in arterial pressure, with the resultant fall in capillary pressure, occurred during these experiments and accounted for the fact that the plasma volume was well maintained, in spite of the marked decrease in the amount of circulating protein. Measurements in 3 dogs indicated that a significant drop in arterial pressure had not occurred.

In the uninjured animals, the intravenous administration of an amount of physiological saline solution equivalent to their body weight produced generalized edema and some loss of protein from the blood stream. It is not possible to estimate the protein concentration of the edema fluid from the amount of protein apparently lost from the blood stream and the quantity of fluid retained because new protein may have been added to the blood stream during the experiment. Assuming that no protein is added to the plasma, the edema fluid would have contained from 0.1 to 0.25 gram of protein per $100 \mathrm{cc}$. of fluid.

The plasma volume remained unchanged or slightly increased in spite of a moderate fall in the quantity of circulating plasma protein. The decrease in plasma protein was not within the range seen in the traumatized animals, but the observations are consistent with the hypothesis that an increase in volume and pressure of the extracellular fluid is one mechanism by which a normal plasma volume can be maintained in the presence of a decrease in the osmotic pressure of the plasma proteins.

The data obtained from the experiments on both injured and uninjured animals indicate that the amount of extracellular fluid is an important factor in determining the size of the plasma volume. Other observations support this view. In dehydration, the plasma volume is decreased, in spite of the fact that the protein concentration of the plasma is elevated. Thus, in the presence of a small volume of extracellular fluid, the greater than normal osmotic pressure of the proteins is not able to maintain even the normal plasma volume. In the normal subject, a rise in the salt and water content of the body causes the plasma volume to increase. Thus, desoxycorticosterone, which increases the volume of the extracellular fluid, also increases the plasma volume (12). The salt and water retention from cardiac failure increases both the quantity of extracellular fluid and the plasma volume (13).

There are several ways in which an increase in the volume and pressure of extracellular fluid might enable the body to maintain a normal plasma volume, despite a marked lowering of the quantity of plasma protein. An increase in extracellular fluid pressure might cause (1) fluid to pass more slowly from the arterial end of the capillary into the tissues; (2) fluid to flow more rapidly from the tissues into the venous end of the capillary; (3) an increase in lymph flow. It is probable that all three of these mechanisms are operative.

Patients who have a marked lowering of the quantity of circulating protein, as in nephrosis and nutritional edema, are able to have a plasma volume large enough to maintain an adequate circulation because of the marked increase in the volume and pressure of the extracellular fluid. In normal subjects after extensive injury to the capillaries of the extremities, the plasma volume quickly becomes too small to support a normal circulation, because the quantity of protein in the blood rapidly diminishes as protein leaks through the in- 
jured capillaries into the tissues. It is probable that if physiological saline solution was given intravenously in large enough quantities, the increase in the volume and pressure of the extracellular fluid would be sufficient to keep the plasma volume at a level adequate to maintain a normal circulation. This is not practical in the treatment of patients because of the enormous quantity of saline solution which would be required. It is obvious that in shock caused by the loss of plasma at the site of injury, it is much more efficient to give plasma than physiological saline solution. When plasma is given intravenously, it leaks out through the injured capillaries until the capillaries recover. If sufficient plasma is given, however, to keep the quantity of plasma protein at a normal level, fluid is lost from the blood stream only in the area of injury, and an increase in the extracellular fluid content of all the tissues is not necessary to keep the plasma volume at a normal level.

The plasma volume is really a part of the extracellular fluid volume. A portion of this fluid is kept in the vascular bed because the sum of the forces causing fluid to leave the blood stream is balanced by the sum of the forces causing fluid to enter it. The osmotic pressure of the plasma proteins and the extracellular fluid pressure are the two forces which balance the capillary pressure. If the osmotic pressure of the protein is decreased, the plasma volume will become smaller unless the capillary pressure falls or the extracellular fluid pressure rises. An increase in extracellular fluid pressure can compensate for a marked decrease in the osmotic pressure of the plasma proteins. This is the reason why patients with nephrosis maintain an adequate plasma volume. A rise in capillary pressure normally causes a decrease in the plasma volume. This can be prevented if the extracellular fluid pressure is elevated. Thus, an increase in extracellular fluid pressure is one of the mechanisms by which patients with cardiac failure maintain a large plasma volume in the presence of high venous and capillary pressures.

\section{SUM MARY AND CONCLUSIONS}

1. The quantity of plasma protein was reduced in dogs by injuring the capillaries of 2 to 4 extremities by a 5- to 6-hour period of arterial occlusion, produced with tourniquets. After release of the tourniquets, the dogs were given physiological saline solution, intravenously, in large quantities. The infusion maintained the circulation at a normal level, and there was a continued loss of plasma into the extremities. The plasma protein concentration, therefore, fell to a low level.

2. If the saline infusion was stopped in the first few hours after the release of the tourniquets, the plasma volume decreased rapidly in size, and signs of circulatory insufficiency developed. The quantity of protein in the circulation was not sufficient to maintain an adequate plasma volume. If the saline infusion was continued until the animal developed sufficient generalized edema, no further tendency to hemoconcentration was noted, in spite of the fact that the quantity of circulating protein was still 50 per cent or more below the level present before the tourniquets were applied. The plasma volume was either normal or moderately reduced. At this time, the circulation and arterial pressure were normal.

3. Uninjured anesthetized animals who received large amounts of physiological saline solution intravenously, developed generalized edema but showed much less decrease in total circulating protein than did the injured animals. The moderate fall which occurred in circulating plasma protein was not accompanied by a decrease in plasma volume.

4. The quantity and pressure of the extracellular fluid is as important in determining the size of the plasma volume as is the quantity of circulating plasma protein. A marked decrease in the osmotic pressure of the plasma protein can be compensated by a marked increase in the pressure of the extracellular. fluid, without affecting the circulation or the size of the plasma volume.

The work described in this paper was done under a contract, recommended by the Committee on Medical Research, between the Office of Scientific Research and Development and the Emory University School of Medicine. It was carried out with the technical assistance of Rosamond Piotti, S.B.

\section{BIBLIOGRAPHY}

1. Freeman, N. E., and Wallace, W. M., Effect of concentrated serum on plasma volume and serum protein concentration. Am. J. Physiol., 1938, 124, 791.

2. Ebert, R. V., Stead, E. A., Jr., and Gibson, J. G., II, Response of normal subjects to acute blood loss. Arch. Int. Med., 1941, 68, 578. 
3. Madden, S. C., and Whipple, G. H., Plasma proteins : Their source, production, and utilization. Physiol. Rev., 1940, 20, 194.

4. Warren, J. V., and Stead, E. A., Jr., The effect of the accumulation of blood in the extremities on the venous pressure of normal subjects. Am. J. M. Sc., 1943, 205, 501.

5. Stead, E. A., Jr., and Ebert, R. V., Studies on Human Albumin. Section in Blood Substitutes and Blood Transfusion, Mudd, Stuart, and Thalheimer, William. C. C. Thomas Pub. Co., Baltimore, 1942, p. 185.

6. Harris, A. W., and Gibson, J. G., II, Clinical studies of the blood volume. VII. Changes in blood volume in Bright's disease with or without edema, renal insufficiency, or congestive heart failure, and in hypertension. J. Clin. Invest., 1939, 18, 527.

7. Chang, H. C., Plasma protein and blood volume. Proc. Soc. Exper. Biol. and Med., 1932, 29, 829.

8. Gibson, J. G., II, and Evans, W. A., Jr., Clinical studies of blood volume: Clinical application of method employing azo dye "Evans blue," and the spectrophotometer. J. Clin. Invest., 1937, 16, 301.

9. Koch, F. C., and McMeekin, T. L., A new direct Nesslerization micro-Kjeldahl method and a modification of the Nessler-Folin reagent for ammonia. J. Am. Chem. Soc., 1924, 46, 2066.

10. Bywaters, E. G. L., and Popjak, G., Experimental crushing injury. Surg., Gynec. and Obst., 1942, 75, 612 .

11. Wilson, H., and Roome, N. W., Effects of constriction and release of extremity: Experimental study of tourniquet. Arch. Surg., 1936, 32, 334.

12. Thorn, G. W., and Emerson, K., Jr., The rôle of gonadal and adrenal cortical hormones in the production of edema. Ann. Int. Med., 1940, 14, 757.

13. Seymour, W. B., Pritchard, W. H., Longley, L. P., and Hayman, J. M., Jr., Cardiac output, blood and interstitial fluid volumes, total circulating serum protein and kidney function during cardiac failure and after improvement. J. Clin. Invest., 1942, 21, 229. 